\title{
Analysis of Influencing Factors of Silt Solidified Soil in Flowing State
}

\author{
Jihui Ding, Zhongmin Feng, Dongxu Sun, Kaikai You, Minghui Yan, Yalei Xun \\ Institute of Civil Engineering, University of Hebei, Baoding, China \\ Email: 1774547891@qq.com
}

How to cite this paper: Ding, J.H., Feng, Z.M., Sun, D.X., You, K.K., Yan, M.H. and Xun, Y.L. (2019) Analysis of Influencing Factors of Silt Solidified Soil in Flowing State. World Journal of Engineering and Technology, 7, 455-464.

https://doi.org/10.4236/wjet.2019.73033

Received: July 6, 2019

Accepted: August 17, 2019

Published: August 20, 2019

Copyright $\odot 2019$ by author(s) and Scientific Research Publishing Inc. This work is licensed under the Creative Commons Attribution International License (CC BY 4.0).

http://creativecommons.org/licenses/by/4.0/

\begin{abstract}
Every year, a large amount of silt is generated by river dredging. For the characteristics of dredging silt, such as high moisture content, low strength and high compressibility, the traditional solidification method can no longer better solve this kind of silt problem. This paper mainly studies the fluidized solidification treatment of high water content sludge, not only makes the silt soil achieve a good solidification effect, but also the project cost is lower, the construction method is more environmentally friendly and green. The influencing factors of the solidified soil are mainly investigated by the unconfined compression test and the fluidity test. The experiment result shows 1) When the cement to sludge mass ratio $\left(R_{C S}\right)$ is $0.09-0.16$ and the fly ash to cement mass ratio $\left(R_{F C}\right)$ is $0.35-0.80$, as the amount of $R_{F C}$ increases, the flow rate of the solidified soil gradually decreases. With the increase of time, the liquidity is significantly reduced, and the influence of cement on the fluidity is greater than that of fly ash. 2) When $R_{C S}=0.09-0.16$, the strength of the sludge solidified soil at $28 \mathrm{~d}$ age increased by $4.5-6$ times. 3) When $R_{C S}=0.09$ - 0.16 and $R_{F C}=35 \%-80 \%$, the intensity of $14 \mathrm{~d}$ increased by 1.23 times than that of $7 \mathrm{~d}$, and the intensity of 28 days increased by 1.29 times than that of 14 $\mathrm{d}$. This experiment can provide the mix ratio design of solidified materials for different needs of the project, which can better provide a basis for engineering application and strength prediction.
\end{abstract}

\section{Keywords}

Flowing Solidified Sludge, Influencing Factors, Fluidity, Unconfined Compressive Strength

\section{Introduction}

China is a country with a large water area, and thousands of lakes. The large 
amount of silt produced every year is a major problem that we face. According to statistics, the annual dredging volume of large and medium-sized dredging enterprises nationwide reached 1.3 billion cubic meters. The dredged soil has high initial moisture content, high compressibility, low strength, long self-weight consolidation time, and is difficult to directly use and occupies a large amount of yardland [1]. The flow curing treatment method is more suitable for this high water content dredged sludge. Compared with the previous principle of water cut rate, the fluidization treatment is to increase the moisture content of the silt and add a curing agent to make it flow, which greatly reduces the engineering cost and improves the engineering quality. No need for pre-pressing treatment, it can take advantage of its fluidity and self-hardening characteristics, without compression molding, and can directly adopt the pumping construction method [2]. This method can reduce noise and environmental pollution and meet the requirements of green construction.

Wang Dongxing [3] used $\mathrm{MgO}$ as a solidification material for sludge to analyze the appearance quality stress-strain relationship and unconfined compressive strength of samples under different immersion time. It was found that $\mathrm{MgO}$ can significantly change the water stability of solidified sludge. Wang Yuhua [4] eliminated the influence of organic matter by adding alkaline oxidant to the solidified sludge. It was found that the $7 \mathrm{~d}$ unconfined compressive strength of the solidified sludge reached $1.536 \mathrm{MPa}$, and the strength was $121.6 \%$ higher than that of cement-solidified sludge. Zhang Rongjun [5] and others used cement as the solidified material of sea mud, and found that the curing temperature has a significant impact on the strength development. The high curing temperature not only significantly increases the early strength of the solidified sludge, but also significantly increases the late strength of the solidified sludge. Boutoui et al. [6] also proposed various strength prediction formulas. More scholars have studied the solidified materials. Shao Wei [7] conducted an experimental study on cement-pulverized ash-reinforced organic soil. Miura, N. [8] and others have shown through experiments that the clay-water-cement ratio is the main parameter for analyzing the strength and deformation behavior of cement soil induced by high water content. The cement bond strength increases as the clay water to cement ratio decreases. Yong Yong [9] added cement lime and other solidified materials to the sludge to form a physical and chemical reaction with the sludge and pore water to increase the strength of the sludge.

Fluidity is the main indicator for describing flow-solidified sludge [10]. Gu Huanda [11] and others summarized the liquidity measurement method and liquidity index. Ding Jianwen, Zhang Shuai et al. [12] and other experiments through the high-water content dredging sludge flow curing treatment, found that the initial water content, the amount of curing agent and the time after preparation have a certain impact on the flowability of the flowing soil. And after the addition of gypsum in the curing agent, the curing strength far exceeds the strength of the cement only. The fluidity test is first seen in the determina- 
tion of the workability of the concrete to evaluate the pumpability of the concrete mixture. This article is aimed at high moisture content sludge, starting from the concept of "disposing waste with waste" [2]. In this paper, composite cement and fly ash were used as curing agent materials to study and analyze sludge solidified soil and the factors affecting fluidity and strength were analyzed.

\section{Experimental Material and Material Content Ratio}

\subsection{Experimental Material}

The sludge used in this test was taken from the Baiyangdian marshland, and the sampling position was $5-15 \mathrm{~cm}$ below the surface layer. The initial moisture content was $52 \%$, and water was added to increase the moisture content to $160 \%$ of the slurry. The liquid limit is $38.2 \%$ and the plastic limit is $26.2 \%$. It belongs to the clay soil. The solidified material is made of cement and fly ash. The cement is made of P.O42.5 ordinary Portland cement. Fly ash is used as the primary auxiliary material. The industrial waste used in the experiment was a silica-alumina low-calcium fly ash.

\subsection{Material Content Ratio}

The experiment uses $1 \mathrm{~L}$ of mud as a unit amount, Cement content: $110 \mathrm{~g}-200$ g, i.e. $R_{C S}=0.09-0.16$; Cement fly ash: cement quality $35 \%-80 \%$, i.e. $R_{F C}=0.35$ - 0.8; Cement phosphogypsum: $10 \mathrm{~g}$. The specific experimental material dosage scheme is shown in Table 1.

Table 1. Material content ratio scheme.

\begin{tabular}{ccccccc}
\hline Numbering & Silt $(\mathrm{g})$ & Cement (g) & Fly ash (\%) & Plaster (g) & $R_{C S}$ & $R_{F C}$ \\
\hline A1 & 1258 & 110 & 35 & 10 & 0.09 & 0.35 \\
A2 & 1258 & 110 & 50 & 10 & 0.09 & 0.5 \\
A3 & 1258 & 110 & 65 & 10 & 0.09 & 0.65 \\
A4 & 1258 & 110 & 80 & 10 & 0.09 & 0.8 \\
B1 & 1258 & 140 & 35 & 10 & 0.11 & 0.35 \\
B2 & 1258 & 140 & 50 & 10 & 0.11 & 0.5 \\
B3 & 1258 & 140 & 65 & 10 & 0.11 & 0.65 \\
B4 & 1258 & 140 & 80 & 10 & 0.11 & 0.8 \\
C1 & 1258 & 170 & 35 & 10 & 0.14 & 0.35 \\
C2 & 1258 & 170 & 50 & 10 & 0.14 & 0.5 \\
C3 & 1258 & 170 & 65 & 10 & 0.14 & 0.65 \\
C4 & 1258 & 170 & 80 & 10 & 0.14 & 0.8 \\
D1 & 1258 & 200 & 35 & 10 & 0.16 & 0.35 \\
D2 & 1258 & 200 & 50 & 10 & 0.16 & 0.5 \\
D3 & 1258 & 200 & 65 & 10 & 0.16 & 0.65 \\
D4 & 1258 & 200 & 80 & 10 & 0.16 & 0.8 \\
\hline & & & & & & \\
\hline
\end{tabular}




\section{Introduction to Duncan-Chang Model}

Figure 1 shows the relationship between the fluidity of the sludge and the amount of curing agent. The effect of cement content and fly ash content on the fluidity of sludge solidified soil was studied. As can be seen from the figure, the amount of the curing agent has a significant influence on the fluidity, and the fluidity decreases as the amount of the curing agent increases. The fluidity index of the solidified soil is between 27 and $36 \mathrm{~cm}$. Since the curing agent does not completely react with the water in the slurry at the beginning, the initial fluidity is large.

As can be seen from Figure 2, as time increases, the liquidity decreases significantly,

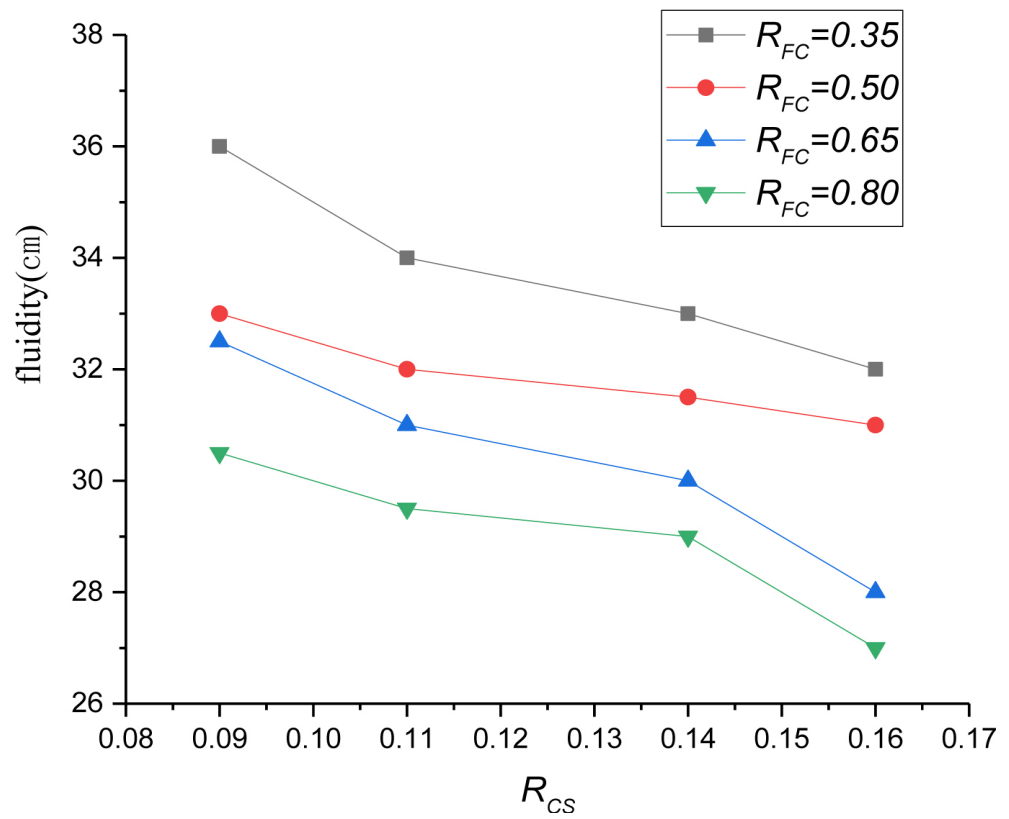

Figure 1. Relationship between curing agent dosage and fluidity.

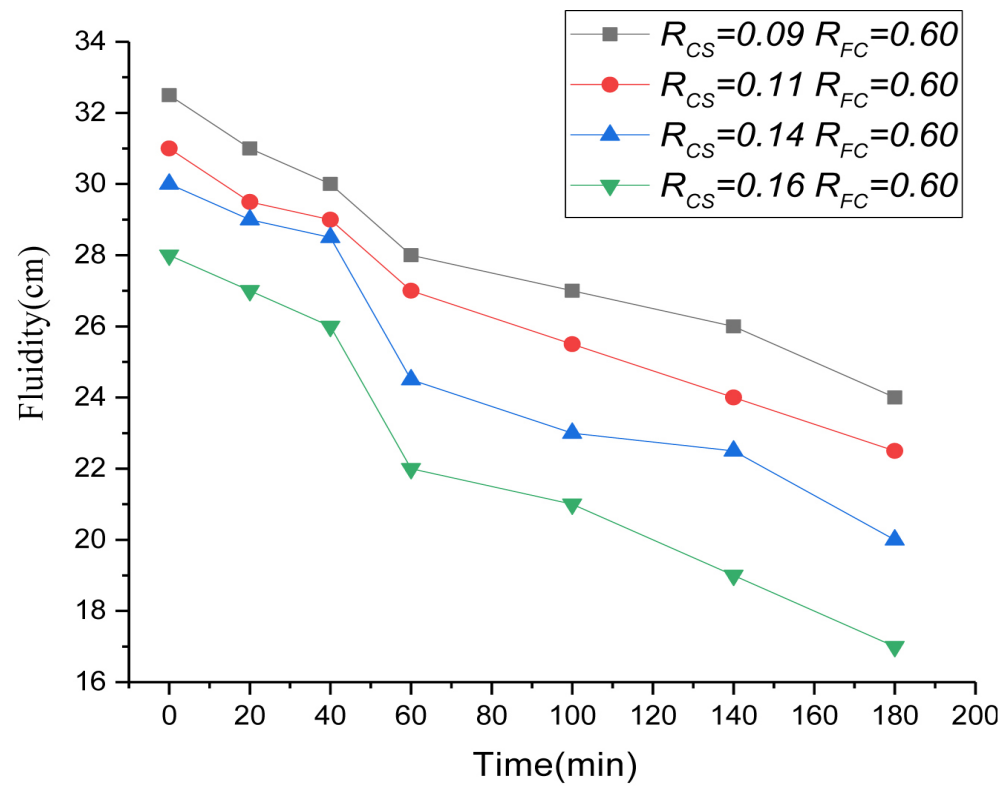

Figure 2. The relationship between time and liquidity. 
The liquidity decreases slowly during the period of $0-40 \mathrm{~min}$, and the variation range is between $32.5-27 \mathrm{~cm}$. The fluidity decreased significantly during the 40 - $60 \mathrm{~min}$ period, and the variation ranged from 30 to $23.5 \mathrm{~cm}$. The flow rate decreases slowly during the period of $60-180 \mathrm{~min}$, and the variation range is between $27-18 \mathrm{~cm}$. After being placed for 3 hours, the fluidity is as low as $18 \mathrm{~cm}$, which meets the requirements of pumping and construction of the flowing soil.

\section{Analysis of Factors Affecting Strength}

\subsection{Impact of Environmental Conditions on the Strength of Curing}

Adjust the temperature of the Constant temperature and humidity box to $20^{\circ} \mathrm{C}$, $30^{\circ} \mathrm{C}$ and outdoor natural conditions, the outdoor time is $14 \mathrm{~d}$, and the time period is from early May to mid-May. The highest average daytime temperature in the outdoor is $23^{\circ} \mathrm{C}$, and the lowest average temperature in the night is $6^{\circ} \mathrm{C}$. The average temperature difference between day and night is $12^{\circ} \mathrm{C}$, and there is rainfall for 2 and half days. Figure 3(a) shows the relationship between unconfined compressive strength and $R_{C S}$ in solidified soil when $R_{F C}=0.65$. It can be seen from Figure $3(\mathrm{a})$ that the strength of the solidified soil under outdoor natural conditions is higher in three different environments. And as the amount of cement and fly ash is increased, the highest strength of solidified sludge at $30^{\circ} \mathrm{C}$. The lowest strength is the solidified sludge at $20^{\circ} \mathrm{C}$, the sludge at $30^{\circ} \mathrm{C}$ is 1.23 times the strength of the sludge at $20^{\circ} \mathrm{C}$.

It can be seen from Figure $3(\mathrm{~b})$ that when the amount of cement is certain $\left(R_{C S}=0.14\right)$, the strength of the solidified soil at $30^{\circ} \mathrm{C}$ is not much different from the strength under outdoor natural conditions, but both are stronger than the strength of the solidified soil at $20^{\circ} \mathrm{C}$. When the amount of fly ash is $R_{F C}=0.5$, the strength of the solidified soil under outdoor conditions is 1.36 times the strength of $20^{\circ} \mathrm{C}$

\subsection{Effect of Curing Age and Dosage on Strength}

As can be seen from Figures 4-6, When the cement content is: $R_{C S}=0.09-0.16$, the strength of the sludge solidified soil increases with the increase of cement content, and the strength can be increased by 4.5 - 6 times, indicating that the cement content plays an important role in strength. When the cement content is $R_{C S}=0.09-0.14$, the amount of fly ash is increased, and the strength of the solidified soil is not obvious. However, when the amount of cement is $R_{C S}=0.16$ and the proportion of fly ash $R_{F C}$ increases from $35 \%$ to $65 \%$, the strength can be increased by 1.72 times. However, the amount of fly ash continued to increase, and the strength of the solidified soil decreased. This also shows that when the cement content is 0.16 , the optimum dosage of fly ash is $65 \%$, so the excessive addition of fly ash has little effect on the strength increase. When the cement content is low, too much fly ash is added, which will reduce the strength of the solidified soil.

As can be seen from Figures 4-6, the strength of the sludge solidified soil and 

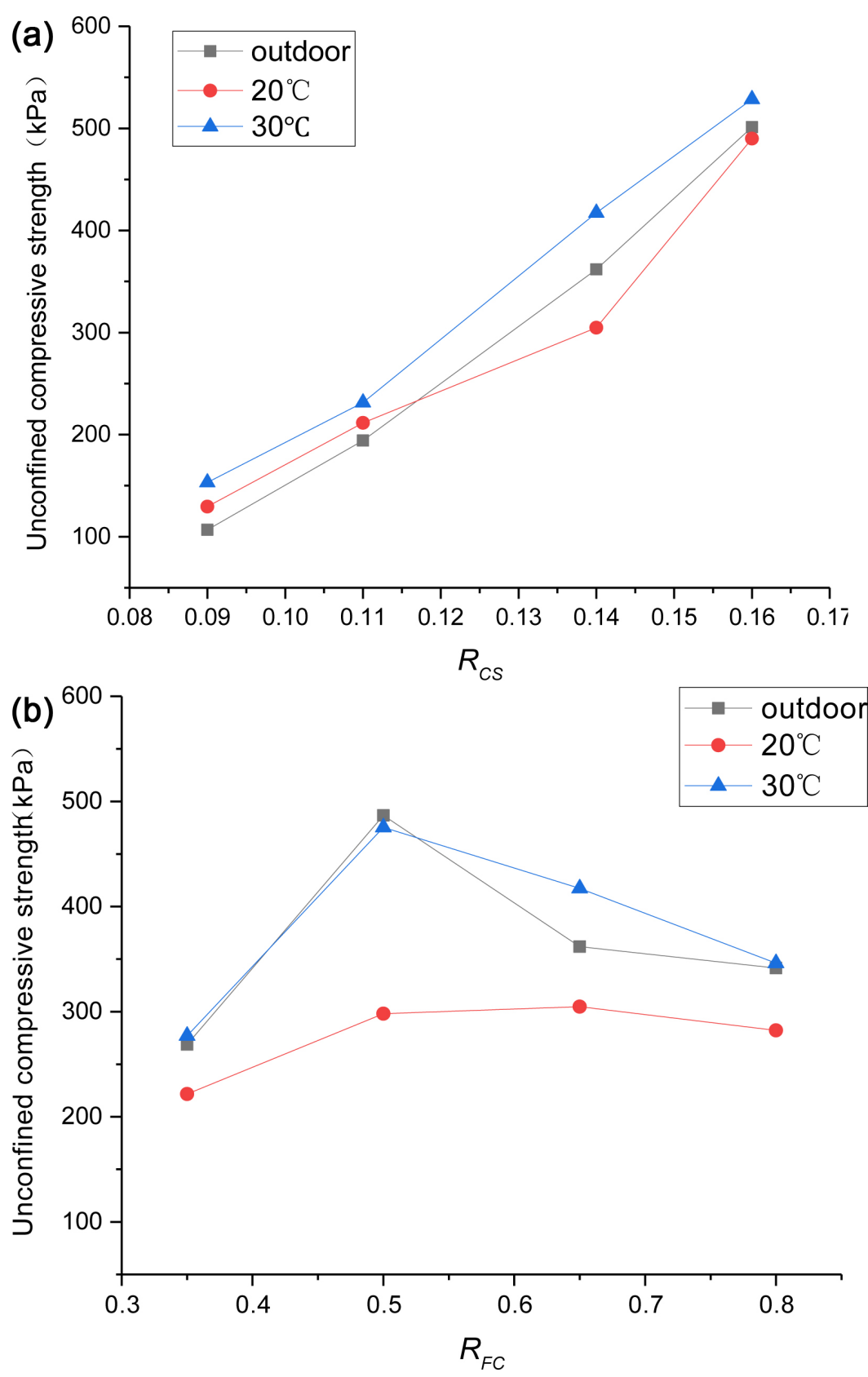

Figure 3. Variation of unconfined compressive strength h at $14 \mathrm{~d}$ at different temperatures. (a) Cement content $R_{C S}\left(R_{F C}=0.65\right)$; (b) Fly ash content $R_{F C}\left(R_{C S}=0.14\right)$.

the curing time are in an increasing relationship. When the ratio of cement is $R_{C S}=0.11-0.16$ and the amount of fly ash is $R_{F C}=65 \%-80 \%$, the strength at $28 \mathrm{~d}$ curing age is $1.25-1.6$ times the intensity of $14 \mathrm{~d}$. However, when the amount of cement and fly ash is relatively small, the effect of curing time on strength is not obvious. When the curing time is short, the effect of cement on the strength of the solidified soil is greater than that of the fly ash. This also means that the solidifying agent of fly ash must function after reaching a certain value at the age.

According to the fitting results of Figure $7 \&$ Figure 8, Equations (1)-(2) give 


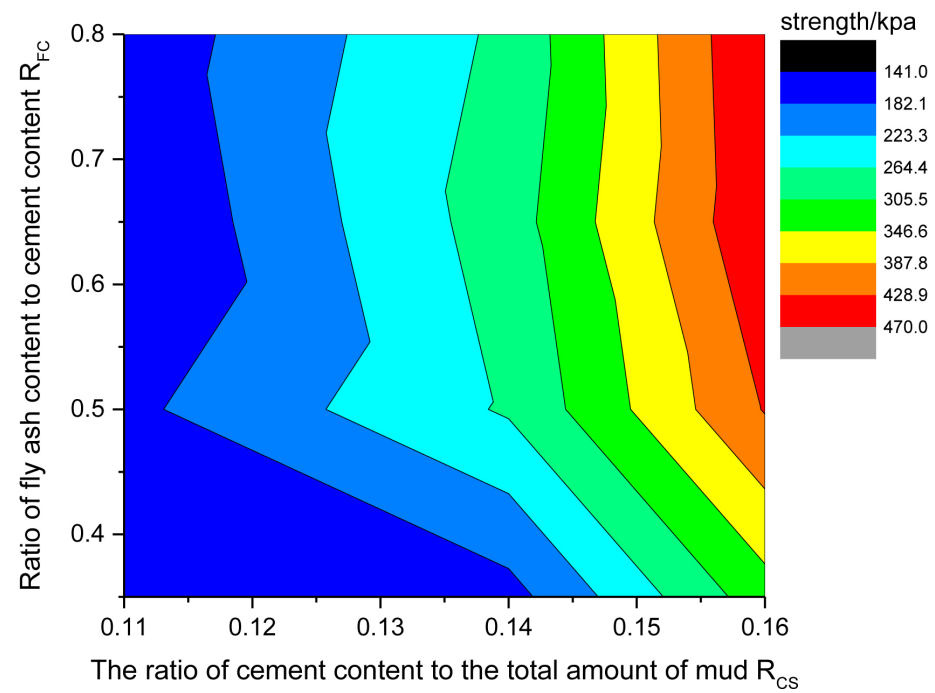

Figure 4. $\mathrm{q}_{\mathrm{u}-7 \mathrm{~d}} / \mathrm{kPa}$.

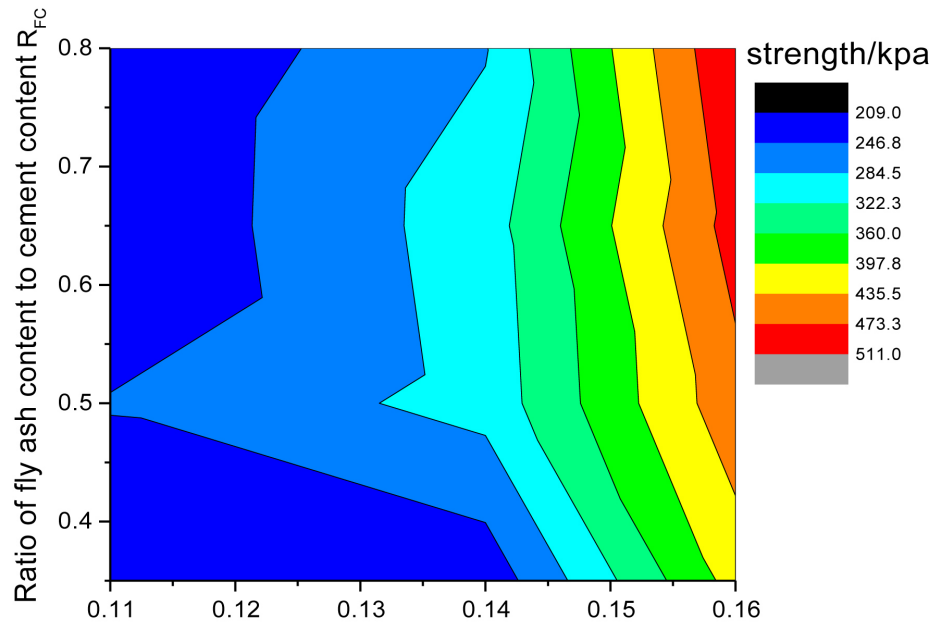

The ratio of cement content to the total amount of mud $R_{C S}$

Figure 5. $\mathrm{q}_{\mathrm{u}-14 \mathrm{~d}} / \mathrm{kPa}$.

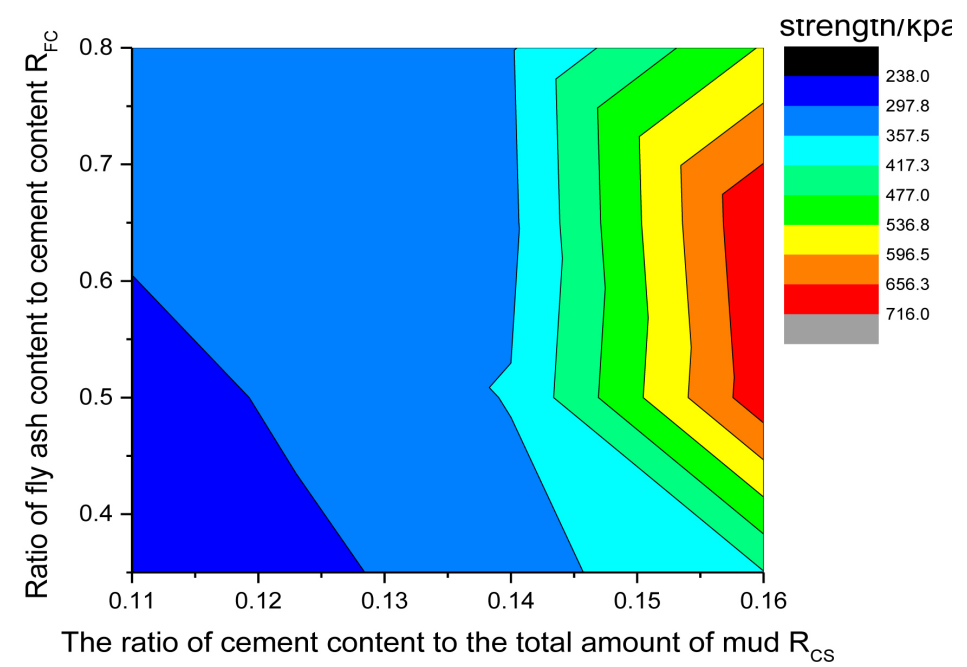

Figure 6. $\mathrm{q}_{\mathrm{u}-28 \mathrm{~d}} / \mathrm{kPa}$. 


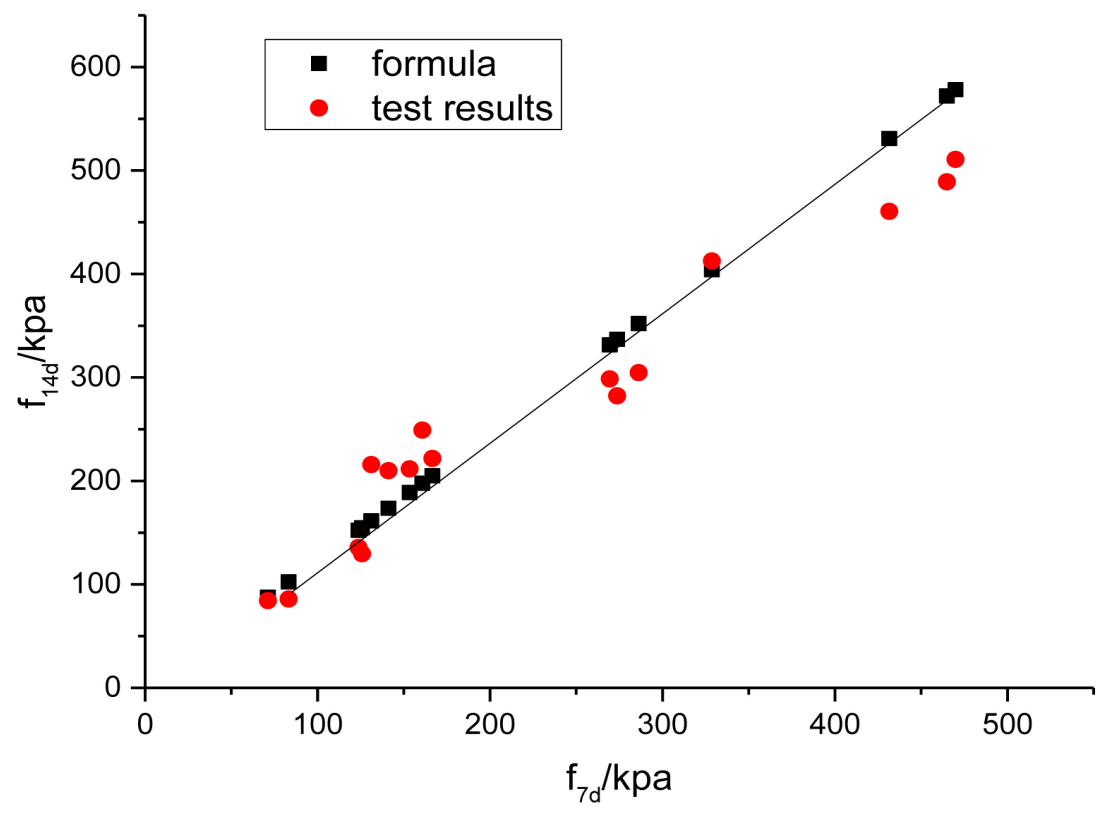

Figure 7. Relationship between $f_{7 d}-f_{14 d^{*}}$

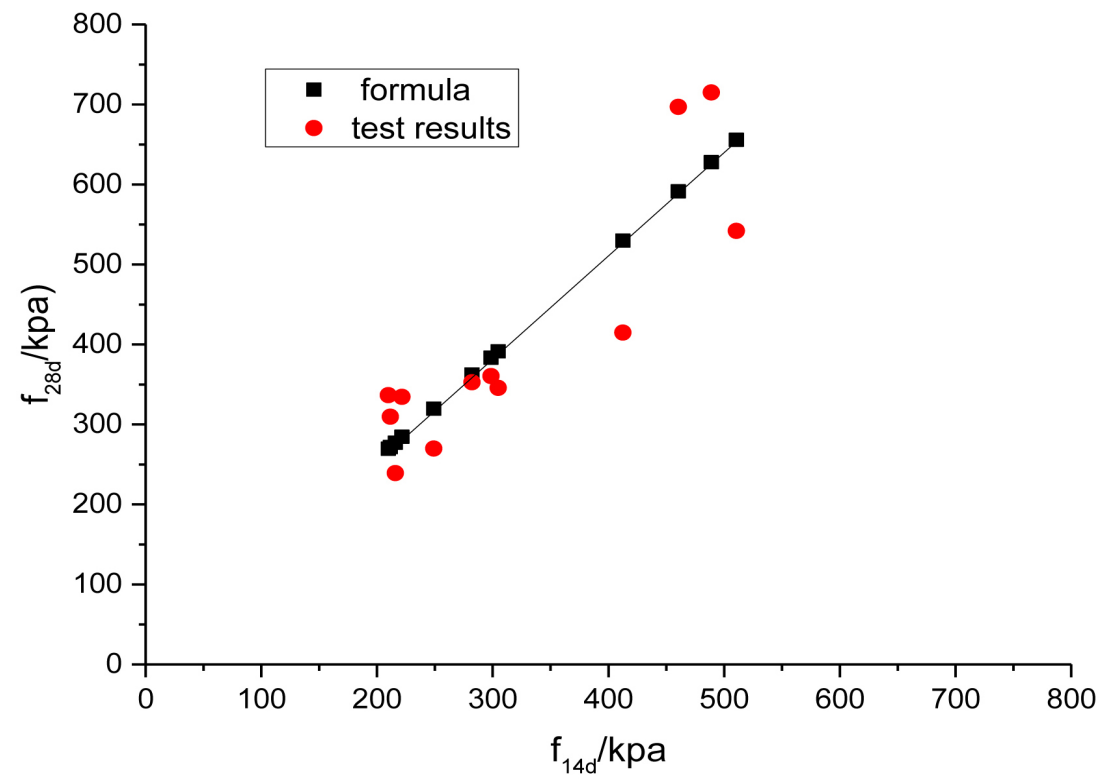

Figure 8. Relationship between $f_{14 d}-f_{28}$.

the relationship between curing time and strength. It can better judge the strength and provide valuable reference for the project. It can be seen that the intensity of $14 \mathrm{~d}$ is 1.23 times higher than that of $7 \mathrm{~d}$, and the intensity of 28 days is 1.29 times higher than that of $14 \mathrm{~d}$.

$$
\begin{aligned}
& f_{14 \mathrm{~d}}=1.23 f_{7 \mathrm{~d}} \\
& f_{28 \mathrm{~d}}=1.23 f_{14 \mathrm{~d}}
\end{aligned}
$$

\section{Conclusions}

1) When the cement content $\left(R_{C S}=0.09-0.16\right)$ and the fly ash content $\left(R_{F C}=\right.$ 
$35 \%-80 \%)$, the fluidity of the sludge solidified soil decreases linearly with time, and the fluidity decreases with the amount of solidified material. When $R_{C S}=$ $0.09-0.16$ and $R_{F C}=0.60$, the flow value changes in each time period are different, and the fluidity decreases slowly in the 0 - $40 \mathrm{~min}$ time period

2) When $R_{C S}=0.14, R_{F C}=0.65$, and the curing time is $14 \mathrm{~d}$, the sludge at $30^{\circ} \mathrm{C}$ is 1.23 times the strength of the sludge at $20^{\circ} \mathrm{C}$. When the amount of cement is $R_{C S}=0.14$ and the amount of fly ash is $R_{F C}=0.5$, the strength of the solidified soil under outdoor conditions is 1.36 times the strength of $20^{\circ} \mathrm{C}$.

3) When the cement content is: $R_{C S}=0.14-0.16$ and the curing time is $28 \mathrm{~d}$, the strength of the sludge solidified soil increases with the cement content, and the strength of the solidified soil can increase by $4.5-6$ times. When the cement content is $R_{C S}=0.09-0.14$, the amount of fly ash increased, and the strength of the solidified soil not significantly increased. However, when the amount of cement is $R_{C S}=0.16$, the proportion of fly ash $R_{F C}$ increases from $35 \%$ to $65 \%$, and the strength can increase by 1.72 times.

4) When $R_{C S}=0.09-0.16$ and $R_{F C}=35 \%-80 \%$, the intensity of $14 \mathrm{~d}$ increased by 1.23 times than that of $7 \mathrm{~d}$, and the intensity of 28 days increased by 1.29 times than that of $14 \mathrm{~d}$.

\section{Conflicts of Interest}

The authors declare no conflicts of interest regarding the publication of this paper.

\section{References}

[1] Zhou, Y., Pu, Y. and Li, Z. (2019) Horizontal Drainage Board-Vacuum Preloading Combined Treatment of High Water Content Dredging Sludge Model Test. Journal of Rock Mechanics and Engineering, 35, 3246-3251.

[2] Ding, J., Liu, T. and Cao, Y. (2013) Pressure Test and Strength Prediction of High Moisture Content Dredged Sludge Solidified Soil. Chinese Journal of Geotechnical Engineering, 35, 55-60.

[3] Wang, D., Wang, H. and Xiao, J. (2018) Experimental Study on Water Stability Characteristics of Activated MgO Solidified Sludge. Journal of Geotechnical Engineering, 52, 719-726.

[4] Wang, Y., Xiang, W., Wu, X. and Cui, D. (2019) Study on the Effect of Alkaline Oxidant on the Strength of Cement Solidified Sludge. Chinese Journal of Geotechnical Engineering, 41, 693-699.

[5] Zhang, R., Zheng, J., Cheng, Y. and Dong, R. (2016) Experimental Study on Influence of Curing Temperature on Cement Solidified Sludge Strength. Rock and Soil Mechanics, 37, 3463-3471.

[6] Boutouil, M. and Lcvacher, D. (2005) Effect of High Initial Water Content on Cement-Based Fludge Solidification. Ground Improvement, 9, 169-174. https://doi.org/10.1680/grim.2005.9.4.169

[7] Shao, Y., Liu, S., Du, G., et al. (2008) Experimental Study on Cemented Fly Ash to Reinforce Organic Soil. Journal of Engineering Geology, 16, 408-413.

[8] Miura, N., Horpibulsuk, S. and Nagaraj, T.S. (2001) Engineering Behavior of Cement Stabilized Clay at High Water Content. Soils and Foundations, 41, 33-45. 
https://doi.org/10.3208/sandf.41.5_33

[9] Yong, Y. (2000) Experimental Study on Soft Soil Reinforced by Cement-Based Curing Agent Containing Industrial Waste. Chinese Journal of Geotechnical Engineering, 22, 210-213.

[10] Ding, J., Hong, Z. and Liu, S. (2011) Experimental Study on Flow Curing Treatment and Fluidity of Dredged Sludge. Rock and Soil Mechanics, 32, 280-284.

[11] Gu, H. and Chen, S. (2002) Experimental Study on Fluidization Treatment of River Silt and Its Engineering Properties.. Chinese Journal of Geotechnical Engineering, 24, 108-111.

[12] Ding, J., Zhang, S., et al. (2009) Experimental Study on Flow Solidification Treatment of High Water Content Dredged Sludge. Water Transport Engineering, No. 6, 30-34. 